1906 at the instance of Sir S. Eardley Wilmot, provision was made for research work in sylviculture, forest botany, zoology, and chemistry, as well as in forest economic products. A scheme now under consideration contemplates a large increase in the establishment and equipment of this institute, involving the acquisition of a site of 1000 acres and an expenditure of some $500,000 l$.

It is interesting to note that, as the work of the Forest Department has increased in volume and complexity, the organisation which sufficed when forest work was relatively simple and of a routine. nature has proved to be no longer suitable, and in recent years there has been a considerable advance in the direction of decentralisation. Thus the major provinces now have complete control over their forest revenue and expenditure, while the provincial chief conservators carry out many of the duties which previously were performed by the head of the department. Similarly, it is now recognised that a great deal of research in sylviculture and economic products must be carried out by local officers in the provinces, and not by the staff of the Central Research Institute at Dehra Dun. At the same time, the value of the assistance and advice which can be obtained from officers who are given opportunities of studying those aspects of problems which are usually not accessible to local provincial officers is fully realised. The Forest Department, in this respect, appears to have realised from actual experience the importance of (I) freedom for the development of local initiative, and (2) mutual good-will, which renders possible loyal co-operation and coordination of work for the common good-principles which, after all, constitute the foundation of the British Empire itself.

In a recent publication issued by the Government of India it is noted that the Indian forest estate constitutes a "huge mine of wealth, the fringe of which has been barely touched," and whether regarded from the commercial or the scientific point of view the magnitude and manysided interest of the work which lies before the officers of the Indian Forest Department to-day can scarcely be surpassed. Finally, the forest officer in India who is brought into intimate contact with men of all degrees, ranging from the aboriginal tribes of remote forest tracts to captains of industry and scientific experts, has it in his power to do much to promote the good-will and co-operation between men of different classes, occupations, races, and creeds which are so important to-day for the welfare of the British Empire and, indeed, of civilisation itself.

\title{
The Investigation of Gravity at Sea.
}

\author{
By Prof. W. G. Duffield.
}

THE most notable attempt to measure the variation of the force of gravity over the surface of the oceans was that made by Hecker in the early years of the present century; in IgOI he surveyed a track across the Atlantic from Lisbon to Bahia, following this up a few years later with the investigation of the Indian and Pacific Oceans and the Black Sea.

Helmert had developed a formula for the variation of gravity with latitude from observations collected from a large number of land stations, and the immediate object of Hecker's investigation was to test its application to determinations made over great ocean depths. The problem of an oceanographic gravity survey has long fascinated geophysicists, because observations on board ship are practically made from the surface of the geoid, and should lead to the determination of the shape of that much-discussed figure; and what is also of importance, its solution should likewise lead to a knowledge of the extent to which isostatic compensation is complete over otherwise inaccessible parts of the globe.

Since observations of gravity must be made with great accuracy if they are to be of any value for such purposes, the examination of the gravitational acceleration at sea is attended by great diffculties; on a moving ship, rolling and pitching produce vertical accelerations which are individually indistinguishable from deviations from the true value of $g$. Reliance must therefore be placed upon suitable damping devices which will reduce NO. 2675 , VOL. IO6] the effect upon the instruments of such extraneous accelerations, or at least enable their mean value to be determined within narrow limits of error.

Hecker's original method depended upon the simultaneous measurement of the atmospheric pressure by means of a mercury barometer and a boiling-point apparatus; the latter determination is independent of the local value of gravity, and, if equated to $\rho g h$ for the mercury column, gives the necessary information for the evaluation of g. A fine constriction in the barometer tube provided a heavy damping factor which reduced the amplitude of the oscillations of the mercury surface; some of Hecker's instruments recorded photographicallv upon a moving film and provided a trace from which the normal level of the mercury might under favourable conditions be gauged.

Hecker considered that his observafions showed that Helmert's formula held good within, roughly, one part in 30,000 for both deep and shallow seas, indicating a high degree of isostatic compensation; his conclusions have, however, been subject to a good deal of unfavourable criticism both on this and on the other side of the Atlantic, and it is true that disappointing inconsistencies appear in successive boiling-point determinations and in the simultaneous readings of the four barometers, which possessed different amounts of "lag," and that in certain other respects objections may be urged which prevent us from accepting the verdict on the evidence placed before us; nevertheless, it was pioneering work, and the difficulties to be 
encountered were largely unknown, and certainly untried, when the investigation was begun. Whether Hecker's conclusion be confirmed or refuted, those who follow will not fail to benefit by his early experiences.

With a view to a further oceanographic gravity survey, Hecker constructed apparatus based upon a different principle, one which had been unsuccessfully tested at sea by William Siemens in 1859 . This time he used a barometer with a sealed cistern, so that the column of mercury should be supported by the pressure of the contained air; the cistern was immersed in a vacuum flask packed with cork shavings to keep the temperature, and therefore the pressure of the air, as steady as possible. Hecker arranged that four of these instruments should be mounted at the corners of a rectangular box containing apparatus for the photographic registration of the heights of the mercury columns. The box was mounted upon central gimbals, designed to maintain the barometers vertical as the ship rolled or pitched. It is clear that if the pressure within the cistern is known from temperature observations, the value of $g$ is obtainable.

Lecturing in July, I913, Prof. A. E. H. Love suggested that the voyage of the British Association to Australia in the following year might afford a valuable opportunity for once more testing the value of gravity at sea, and urged upon British astronomers and physicists the importance of the problem. His appeal proved irresistible. The time for preparation for so great an undertaking was very short; nevertheless, it was found possible, largely through the generous provision of instruments by the Meteorological Office and the Cambridge Scientific Instrument Co., to accumulate apparatus whereby tests could be carried out by three separate methods. Profs. Hecker and Helmert were anxious to have the instrument already described tested at sea, and willingly offered it for trial during the voyage; it was, therefore, brought from Strassburg in June, I914, and installed on s.s. Ascanius in Liverpool.

Of the other pieces of apparatus one depended upon much the same principle as that of Siemens and Hecker-namely, the equilibrium of a column of mercury supported by air pressure within a closed vessel-but there were important differences; it was arranged that the lower surface of the mercury should always be brought to the same level in the cistern, an adjustment determined by an electric contact with a point which completed a telephone buzzer circuit. This ensured a constant volume for the enclosed air. The height of the barometer column was not directly observed, but estimated by measuring the length of the thread of mercury, which it was necessary to introduce into the apparatus through a fine capillary tube in order to secure contact at the lower surface. Assuming that the temperature remained constant, a defect in gravity would demand the addition of mercury in order to lengthen the barometer column sufficiently to balance the pressure of the air in the reservoir. The sensitivity could be made great by adopting a high ratio between the cross-section of the barometer tube and that of the capillary index tube through which the mercury was introduced.

A valuable suggestion for the improvement of this apparatus came from Sir Horace Darwin, who pointed out that the bulk of the difficulty occasioned by fluctuations of temperature might be overcome by employing such a volume of mercury within the apparatus that its expansion would automatically provide the additional height of mercury in the barometer tube necessary to balance the increase of pressure of the air in the reservoir due to a rise in temperature.

The third method consisted in comparing the readings of a mercury barometer with those of an aneroid; both were open to the atmosphere, and, as in the boiling-point method, we have the equation $\Pi=\rho g h$ to give us the variations of $g, \Pi$ being now given by the aneroid, and $h$ and $\rho$ by the barometer and its attached thermometer. The aneroid was specially constructed and kindly lent by Sir Horace Darwin for this research. On board a ship the voyage of which carries it through many degrees of latitude one of the greatest difficulties is to obviate the effects of large changes of temperature. On the outward voyage this difficulty was very largely overcome by the generous installation by Messrs. Alfred Holt and Sons of a special refrigerating chamber on s.s. Ascanius, which served as an excellent laboratory. It was furnished with a separate system of brine pipes, and though at first there were rather large fluctuations, two engineers on day and night duty eventually became so adept at regulating the flow of brine that during the latter stages of the voyage the variation amounted to considerably less than one degree over a period of twenty-four hours, even though the observer was frequently within the chamber for an hour or more at a time. In future work it should, if possible, be arranged that it is not necessary for the experimenter to remain in the chamber for lengthy periods, as it is detrimental to health; but the experience does suggest that it is possible to overcome the very serious difficulty of maintaining a large room at an approximately steady temperature throughout the voyage.

Unfortunately, the outbreak of war at the time the British Association reached the shores of Australia led to the ship being commandeered for troops, so it was not possible to make use of this laboratory on the return voyage, and a good deal of the experience gained was wasted. A place was, however, found in the refrigerating chamber of the P. \& O. R.M.S. Morea for all the apparatus, so the test was continued, though under very unfavourable conditions. on the homeward journey.

It had scarcely been hoped, when the expedition was planned, to do more than obtain experience and information which would serve as a guide for future work upon gravity at sea, and more than this is not claimed for the results. Briefly, it may be stated that leaks which developed in Hecker's apparatus, and a troublesome 
temperature gradient between the cistern and the stem of the barometers, demand radical alterations in its design if it is to be rendered efficient. For the brief period of the voyage when the gravity barometer could be favourably observed, results were obtained which seemed to indicate that the method was one of promise, and it may be of interest to state that new apparatus of this type is in course of construction; the design has been modified in the light of experience gained at sea, and of a mathematical examination of the instrument by Sir Arthur Schuster. One specially favourable feature of the instrument is the possibility of completely immersing it in a constant-temperature bath.

Though the particular aneroid "pumped" with the motion of the ship more than was hoped, and had a reduction factor and zero which changed slightly during the voyage, the aneroid method is one which should be further examined, and certain directions in which alterations in the design are desirable were indicated by the experience on the voyage to Australia. With it the general variation of gravity with latitude over the ocean is readily shown, but whether it may be trusted to discriminate between such variations as may be found over deep and shallow waters must be a matter for further examination. We may note, as a matter of interest, that such indications as were obtained with this method suggested a defect of gravity over great ocean depths, along continental seaboards (especially when there was a coastal range of mountains), and an excess of gravity at island stations; but, as we have stated, a more rigorous test with improved apparatus is necessary before this can be accepted. The problem has therefore arrived at an interesting stage; Hecker's observations are in favour of nearly full compensation, whereas the slight evidence of the later work, so far as it goes, suggests that compensation is incomplete.

Reference has already been made to the instrument constructed in 1859 by William Siemens-in that year he was carried in a warship across the Bay of Biscay, his real object being the determination of ocean depths, which he took for granted would be shown by a diminished value of $g$. Dissatisfied with his first apparatus, he did not make a further attempt until 1875 . When he constructed an instrument which depended upon balancing the pressure of a column of mercury against the tension of a spring, and this he tested on a cable-laying ship over a portion of the voyage between the Thames and Nova Scotia. The results, in spite of anomalies as regards lati- tude variation, which puzzled Siemens, show a surprising measure of agreement between predicted and observed depths, which, so far as they go, are in accord with the aneroid observations just referred to. This must not, however, be overemphasised, since Siemens was dissatisfied with this apparatus. Though not really directed at the solution of the problem under discussionSiemens's "bathometers" were graduated in fathoms-these instruments are of interest in that they appear to have been the first involving gravity measurements to be submitted to an actual test at sea.

Since the Australian meeting of the British Association in 1914, further work has been carried out under the auspices of an influential committee of that body, and certain other points have received attention. From a series of experiments carried out last year on H.M.S. Plucky, it appears that the ship's motion through the air may very appreciably affect the pressure recorded by an open barometer, even when carried in cabins below deck; hence, as the "lag" of this instrument is in general different from that of the instrument with which it is being compared, it is very undesirable to adopt barometers of the open type for gravity determinations. On board the destroyer effects as large as one millibar were found to be due to the relative motion of the ship and the air; no doubt a similar disturbing influence affects the readings of a barometer in a building about which a wind is blowing.

Another matter which was examined on H.M.S. Plucky was the Eötvös effect; going east with the earth, the centripetal force is greater than when steaming west; consequently a correction for motion in longitude is indicated. After eliminating windage effects, a change equivalent to o. I mb. was observed when the course was altered from E. to $W$. when steaming at 22 knots.

There are other points the investigation of which is not yet complete: the best diameter of capillary tubing to be used in the barometer tube to damp down the effects of the ship's vertical motion, the influence of the throbbing of the ship's engines upon the barometer reading-there is some suspicion that certain divergences between gravity readings in harbour and in the open sea may be accounted for by the change in capillary forces due to this cause-the best form of constant-temperature chamber for use at sea, steady to I/Ioo degree: these and allied questions are engaging the attention of those who are contemplating a fresh attack upon the problem.

\section{Obituary.}

Prof. H. A. Bumstead.

THE death of Prof. H. A. Bumstead, professor of physics in Yale University, which occurred with tragic suddenness on January I when he was travelling from Chicago to Washington, will be felt with the keenest regret by a large number of men of science in this country. There are few American men of science with more English friends than had Prof. Bumstead, and none whose friendship and companionship were more highly prized. Born in 1870 , he graduated at Johns Hopkins in 1891. He began in 1893 , as instructor in physics in Sheffield Science School, that connection with Yale which continued without inter-

No. 2675 , VOL. IO6] 